DOI: $10.17805 /$ trudy.2016.3.5

\title{
СТЕРЕОТИПИЗАЦИЯ СОЗНАНИЯ - СЕКРЕТ ВОЗДЕЙСТВИЯ СРЕДСТВ МАССОВОЙ ИНФОРМАЦИИ
}

\author{
В. Л. Артемов \\ (Московский гуманитарный университет)
}

Аннотация: Статья содержит анализ психологического механизма воздействия средств массовой информации на массовое сознание. Разбираются особенности характеристик аудитории массовой коммуникации. Описывается процесс формирования кумулятивного эффекта воздействия СМИ на аудиторию.

Ключевые слова: стереотип; массовая коммуникация; стереопизация сознания; массовое сознание

\section{STEREOTYPING OF MASS CONSCIENCE AS A SECRET EFFECT OF MASS MEDIA}

\author{
V. L. Artemov \\ (Moscow University for the Humanities)
}

Abstract: The author analyses the psychological mechanism of mass media's impact on mass conscience, with a special focus on distinctive features of the audience in mass communication. Also explained is the process of building a cumulative media impact on the audience. The author presents a psychological typology of stereotypes, concluding with a look at the interaction of attitudes and stereotypes as parties to the process of mass communication.

Keywords: stereotype; mass communication; stereotypization of consciousness; mass consciousness

Особенности процесса распространения, потребления и реализация воздействия массовой информации через средства массовой коммуникации связаны, прежде всего, с характером аудитории средств массовой коммуникации. Институциональность и применение мощных технических возможностей распространения контента во времени и пространстве позволяет средствам массовой коммуникации охватывать одновременно необъятные территории, доходить до самых отдаленных и недоступных местностей и одновременно работать с любыми, от немногочисленных групп локализованного населения и профессиональных и т. п. сообществ, до едва ли не беспредельных количеств людей по всей стране, в группе стран или во всем мире. 
Если взять для наглядности пространства России, то средствам массовой информации приходится доносить информацию до крайне рассредоточенной аудитории, живущей в разных часовых поясах, с очень большим разбросом во времени. Одна и та же информация, будучи актуальной для западных областей страны, может оказываться уже запоздалой или устаревшей для восточных. По причине вмешательства местных факторов, их реакция на сообщения может опережать соответствующий отзвук на западе, передаваемая информация может иметь там иное значение, иное звучание, другой акцент.

Фактор рассредоточенности усугубляется разной степенью компактности расселения жителей страны и ее отдельных областей и районов. В условиях сельской местности, малых поселений и городов информация распространяется и производит эффект не так, как в мегаполисе, в малой группе не так, как в большой. Общесоциологический закон двухступенчатого распространения информации, когда переданная по каналам массовой коммуникации информация воспринимается, перерабатывается и усваивается не сразу по факту контакта с ней непосредственно каждым отдельно взятым индивидом-реципиентом, а преимущественно после того, как подвергнется внутригрупповым влияниям. Механизмов таких влияний несколько. Главный среди них - использование природы стереотипизации мыслительной деятельности.

Прежде всего, это авторитет и слово группового лидера мнения вкупе с регулирующим действием конформности. Эти факторы регулируют многообразие впечатлений, нивелируя индивидуальные оценки и выводы до уровня общезначимости, а в отдельных случаях отклонения от таких усредненных величин или их полного неприятия, заставляют «уклонистов» подстраиваться под общее настроение или держать особое мнение про себя.

Ситуация выглядит еще сложнее, если учесть, что средства массовой информации обращаются к анонимной аудитории. Эта аудитория неощутима, никогда не видна, всегда представляется огромной, никак не проявляющей себя безликой массой, из которой проблематично выделить и идентифицировать какие-то конкретные объекты. Мало того, что пред коммуникатором маячит безмолвное море голов, все эти головы разные и каждая, буквально каждая, это свой особый внутренний мир.

Аудитория средств массовой информации неоднородна. Коммуникатору приходится ориентироваться на абстрактные цифры демографической статистики, данные социологических служб или собственную интуицию. Одновременно это огромное число индивидуумов, каждый со своими убеждениями, взглядами, проблемами, представлениями, осведомленностью, каждый принадлежит к разным социально-демографическим и об- 
щественным группам и слоям и отличается происхождением и собственной жизненной историей.

Это значит, что каждый из этого множества воспринимает одно и то же сообщение по-своему, видит под своим углом зрения. Коммуникатору никогда не под силу угадать все разнообразие индивидуальных подходов и точек зрения и, следовательно, с абсолютной верностью определить превалирующие. Почти беспредельная разнородность аудитории массовой коммуникации требует особого подхода к разработке стратегии и тактики информационного воздействия, чтобы массовая коммуникация, всегда имеющая определенное целеположение, обеспечивала требуемую эффективность.

Достижение заданной результативности средств массовой информации затрудняется также таким переменным фактором, как спонтанность аудитории. В каждый данный момент времени аудитория средств массовой информации отличается непостоянством. Кто-то уходит, не дослушав, не досмотрев, не дочитав, кто-то только-только подключился, и нет уверенности, что сегодня в это время мы имеем дело с теми же самыми реципиентами или с тем же их числом и составом, что за час или за день до этого. Приходится подключать исследовательские службы и вырабатывать специальный алгоритм подачи информации, выделять целевую, контактную и т. д. аудиторию, полагаясь на сложившиеся в процессе массовой коммуникации социально-психологические механизмы. Главный из них - стереотипизация мыслительной деятельности - инструмент человеческого познания и язык массовой коммуникации.

Введенное в 1922 г. американским публицистом Уолтером Липпманом в оборот журналистики и психологической науки понятие стереотипа представляло собою типографский термин, обозначающий применявшийся прежде механизм в форме барабана, который, вращаясь, печатал нанесенный на него текст в неограниченном количестве (Lippman, 1972). Позже он был осмыслен в формуле «стереотипы - язык массовой коммуникации», стал не менее стереотипным и, как всякий стереотип, передает явление в самых общих чертах. За этим скрывается очень сложное и неоднозначное явление.

Секрет воздействия стереотипа как языка массовой коммуникации скрывается, прежде всего, в том, что обозначаемое этим термином явление отражает, передает тот или иной объект (явление, факт, тип людей и т. п.) в сжатой, но, что чрезвычайно важно, в предельно упрощенной, легко узнаваемой образной форме. Стереотип-образ передает, в принципе, только определенный абрис объекта, одинаково воспринимаемый и понимаемый большим числом самых разных людей.

Стереотипные представления проявляются, оживают как образы оди- 
наковой окраски и силы, прежде всего в пределах общения определенных социальных групп, как больших, так и малых. Это объясняется одинаковыми для них условиями существования и общими формами протекания процессов жизнедеятельности во всем ее многообразии, а также постоянными и привычными способами такого внутригруппового общении. Очень существенную роль при этом играют традиционные для них источники информации и вырабатывющиеся при этом общие информационные привычки.

В каждой социальной группе в рамках группового общения складываются свои стереотипы, а более широко циркулирующие в обществе стереотипы обогащаются собственным своеобразием, окраской, звучанием, приближающим стереотип-образ к реалиям данной социальной действительности или местной специфики. Отсюда пестрота и своеобразная иерархия стереотипов - от малой группы до самой большой, всеохватывающей, населения страны, региона, мира.

Под стереотипизацией мышления скрывается способность психики закреплять информацию об однородных явлениях, фактах, предметах, процессах, людях и т. д. в обобщенных, устойчивых и единообразных образах. При этом образы упрощаются, утрачивая детали и частности настолько, что одинаково воспринимаются и понимаются всеми членами человеческой общности.

Стереотипизация психических явлений, фиксирующих их в знакомых и понятных для всех людей формах, позволяет людям обмениваться информацией, понимать друг друга, вырабатывать общие взгляды, одинаковые ценностные ориентации, участвовать в совместной деятельности. В условиях стремительно множащихся знаний и сфер человеческой деятельности стереотипизация форм человеческой коммуникации, все больше захватывающая не только массовое общение, но и общение межличностное, является важнейшим условием передачи знаний.

Подавляющее количество знаний о природе, окружающей нас материальной и духовной среде, среде социальной мы получаем не из собственного опыта, а опосредованно, и вынуждены полностью полагаться на чужой опыт и информацию о ней со стороны. Едва ли не первые такие сведения мы получаем в школе, когда сознательно берем на веру, что площадь окружности пи-эр-квадрат. Постепенно у людей складывается обыкновение некритично воспринимать информацию из привычных источников информации, и чем массированнее поток такой информации, тем с большей легкостью воспринимается и усваивается информация. Здесь таится возможность невероятно могущественного влияния стереотипов, едва ли не безграничного и во времени, и в пространстве.

Это не было бы возможным, если бы стереотипы (т. е. схожие обра- 
зы и представления) не имели внешних обозначений, которыми люди и оперируют в общении между собой. При этом стереотипизированные, т. е. содержащиеся в сознании множества людей однозначные психические образования - мыслительные стереотипы, - сливаются в один своеобразный неделимый гибрид с соответствующими им условиями, обозначениями, знаковыми выражениями - общепринятый «код», проявляются, «оживают» в словесных или любых других стереотипах-знаках и без них не смогли бы стать всеобщим достоянием. Все любят свободу, все стремятся к ней, это в мыслях у миллиардов людей во все времена. У всех эти мысли и связанные с ней чувства обозначаются словом «свобода». Оно для всех несет в себе однозначное понятие, что и может приводить в движение умы и действия самых разных людей и социальных групп.

Частным случаем стереотипа-знака являются пропагандистский стереотип или имидж, которые вырабатываются целенаправленно для организованного воздействия на массовое сознание. Всякому профессионалу известно, что для этого используется специальная тактика и методика, в сущности, построенная на использовании природы стереотипизации.

В качестве стереотипа - знака слово несет в себе одинаковое для всех людей «значение», передающее понятие, сущность предмета. В качестве мыслительного стереотипа слова выражает то или иное значение в виде «смысла», передающего индивидуальный оттенок представлений, образов. (Значение «слон» может быть представлен в индивидуальном сознании образом африканского или индийского слона, при этом слон для всех останется слоном, «дом» для всех людей равнозначное понятие как здание, хотя конкретное представление о том, как он выглядит и как устроен, у разных народов неодинаковое).

Люди мыслят понятиями, понятия выражаются словами. Мышление и речь неразделимы, поэтому слово выступает одновременно и внутренним (мыслительным) стереотипом и стереотипом внешним (знаковым). Здесь кроется одна из причин того, что образованные, широко владеющие языком люди менее подвержены слепой стереотипизации мышления. Богатство словарного запаса, умение оперировать синонимическими рядами создают тот фон, который позволяет непроизвольно сужать воздействие общепринятых стереотипов, как бы выводя за их рамки, и раскрывая их смысл в ином ракурсе.

Слово может быть отнесено к разряду общепсихологических стереотипов. С их помощью действительность воспринимается всеми людьми одинаково. Для их характеристики важно учесть то, что заложенные в слове психические образы обозначают общезначимые знания о предмете, но также включают в себя еще и отношение к нему (что он есть для меня). В общепсихологических стереотипах знание является ведущим 
равнозначным для всех компонентом. Слово выступает в этом качестве чаще всего, так как фиксирует сложившиеся в национальном языке понятия или передает общепринятые истины, бесстрастную информацию. Общепсихологические стереотипы обеспечивают функционирование как межличностной, так и всех других видов человеческой коммуникации.

Конечно, массовая коммуникация, как канал массовой информации не может осуществляться иначе, чем с помощью общепсихологических стереотипов, но ее эффективность зависит от стереотипов социальнопсихологических. Такие стереотипы передают не общечеловеческое содержание, а содержание, существенно значимое для данной социальной группы, участников массового коммуникационного общения. Социальнопсихологический стереотип можно определить как укоренившееся в социальной психологии той или иной социальной группы устойчивое отношение к однородным или сходным явлениям. Одинаковая реакция на стереотипы-символы, обозначающие определенный мыслительный стереотип, возможна потому, что люди вкладывают в них один и тот же смысл.

Таким образом, для разных социальных групп, самых разных людей один и тот же стереотип-символ может нести неодинаковое, вплоть до противоположного, смысловое наполнение. Значит, при одном общепсихологическом стереотипе (включающем в себе равнопонятное «значение», как оно закрепилось в данном языке) могут существовать несколько стереотипов социально-психологических. Они появляются и существуют в разных социальных группах, в разных обстоятельствах и при разных состояниях общества.

Яркий пример - разность смысла вкладываемого в слова «свобода» и «демократия». Множество, едва ли не большинство партий с их сторонниками, выступают за право на свободу, борются за демократию. Лозунгстереотип звучит у всех одинаково, но вкладываемый в него смысл существенно разнится. Во время Гражданской войны в США и северные федералисты, и конфедераты-южане вели войну за свободу и демократию. Только рабовладельцы южных штатов отстаивали свое право на свободу владеть рабами и исключительное право белых на управление страной. Северяне стремились установить свободу от рабства и демократию для всех граждан, независимо от цвета кожи. Стереотип свободы был одинаково привлекателен для обеих сторон, какие бы разные цели они не преследовали и как бы неодинаково, по-своему, ни понимали свободу и демократию.

Формы стереотипизации мыслительной деятельности разнообразны. Это и образы, и представления, и оценки и т. п., когда они становятся повторяющимися, устойчивыми, привычными и равнопонятными - и для одного индивида, и для многих людей одновременно. Это может быть и одно слово, и суждение, и умозаключение. Им могут быть и 
различные зрительные, слуховые, обонятельные, вкусовые, осязательнодвигательные образы, выражающие соответствующие виды памяти.

Стереотипы сознания складываются постепенно, в потоке контактов индивидов с окружающим миром, в процессе социализации, общения с другими людьми, формального обучения и воспитания, обращения к средствам массовой информации. Свое содержательное наполнение стереотип получает под воздействием представлений о мире, природе, обществе, об их непосредственном окружении, о людях, с которыми они находятся в непосредственном контакте и условиях существования собственного и других людей.

Здание стереотипа строится из кирпичиков - установок, своеобразных отпечатков, которые оставляют в мозгу человека контакты с внешним миром во всех его ипостасях - объектах физических и духовных. Установка - это готовность мозга определенным образом реагировать на определенного рода информацию, из какого бы источника она ни поступала.

Установка зарождается при первом же контакте с неизвестным объектом, причем любым объектом, когда восприятие его ложится на уже известный опыт, знания, чувственную историю и оказывается, что он представляет собой новое знание, представление, образ. При повторении той же или аналогичной информации эта установка затвердевает, закрепляется, фиксируется. Начинает работать умственная инерция. Теперь всякая новая информация об объекте пропускается через сито этой установки, и изменить ее, поддержанную прошлым опытом и встроившуюся во внутренний мир человека, очень трудно, тем более, если речь идет об установке, ложащейся на почву сходных установок.

Чем фиксированнее установка, тем крепче ее влияние, тем более, когда она формируется на фоне сходных установок на явления или факты того же порядка и той же окраски. Но первый контакт, порождающий новую установку, имеет сакраментальное значение. Как выразился известный теоретик и практик пропаганды: «Человек, сказавший миру первое слов, всегда прав». Дело в том, что новая установка образуется в результате непростого процесса, молнионосного, но очень существенного, когда новая информация соотносится с уже известным знанием и опытом и встраивается в структуру личности, входя в баланс с другими знаниями и представлениями.

Последнее обстоятельство исключительно важно. Не случайно, например, в острые моменты противостояния с Россией западные лидеры неоднократно и скоропалительно публично обвиняли российскую сторону в нарушениях международного права или законов человечности, в открытую манкируя доказательной базой, как это было в случае с гибелью над Украиной малазийского лайнера. Несмотря на очевидную абсурдность вы- 
движения обвинений до того, как начались следственные действия, тем более при весьма противоречивых обстоятельствах, президент США смело пошел на громогласные утверждения. Готовившие его выступление помощники прекрасно понимали, что создаваемая им мрачная установка ложилась на почву столь же негативных представлений и настроений, выращенных в общественном сознании Западного мира тем же самым способом. Снять негативный эффект авторитетного утверждения президента, опровергнуть ее, тут же пустившую глубокие корни в уже подготовленную антироссийской пропагандой почву не удастся даже с помощью самых достоверных и убедительных аргументов. Они элементарно не будут с ходу не только восприниматься, но и просто выслушиваться, будучи заблокированными господствующими русофобскими настроениями.

Для того, чтобы побороть новообретенную или прочно зафиксированную установку, необходимо преодолеть сопротивление множества установок и структур, в которые она вписалась. К тому же и этого мало, нужно, чтобы человек пожелал изменить свой подход, захотел перестроить свое видение объекта. А это часто связано с посягательством на равновесие внутреннего мира человека, его привычную самооценку и убеждения, чувство собственного достоинства, едва ли не всю структуру личности. Изменить взгляды, мнения, оценки, а тем более убеждения, исключительно трудно. Главное условие при этом - предрасположенность слушать иные оценки и соглашаться с иным видением фактов, изменить свои оценки, подходы, взгляды. Как мы это видим в западном обществе относительно представлений о России. Господство отношения над знанием, то есть господство невежества, делает общественное сознание дальтоником, способным видеть Россию только в темных красках.

При поступлении однотипной, особенно той же ценностной ориентации, информации постепенно складывается однонаправленный образстереотип объекта, разбить который очень непросто. Даже когда установка оказывается в силу определенных причин расшатанной, а стереотип поколебленным (что так или иначе происходит как результат ослабления или вытеснения старых установок), все равно прежняя окраска представлений еще очень долго довлеет над восприятием, а иногда так и не исчезает, оставаясь где-то на дне сознания в виде тени сомнения.

Чем сложнее отражаемое в образе-стереотипе явление и чем разнообразнее поступает о нем информация, тем многочисленнее установки, закрепляющие создаваемый образ. Они как бы щетинятся во все стороны, оберегая стереотип от инородных воздействий. Сломить сопротивление сложившейся системы установок по преимуществу под силу только непосредственному опыту, который вытеснит старые, изжившие себя установки и заместить их теми, которые уже не будут отторгаться сложив- 
шейся структурой личности. Но даже и в этом где-то на дне подсознания остается некий осадок, след первоначальной установки.

Социально-психологические стереотипы составляют основу мощного, почти гипнотического влияния средств массовой коммуникации на общественное сознание и массовые настроения.

Важно то, что они выступают своеобразным синтезом всех видов памяти - словесно-логической, образной, зрительной, слуховой, эмоциональной и т. д. Это самое общее выражение, суммарный, эмоциональный итог личного и общественного опыта, который разделяется людьми в форме сопереживания.

С течением времени в памяти людей стирается все, и все перекрывается новыми впечатлениями, событиями, интересами, забываются конкретные вещи, имена, факты, названия. Но вот «вкус», направленность, окраска воспоминаний, впечатлений остается в фиксированной установке, подкрепленной многими другими сходными установками, которые поддерживаются «на плаву» многократным повторением однонаправленных акцентов ценностного характера. В конце концов от всего прошлого опыта сохраняется и даже укрепляется отношение к событию, явлению, человеку. Мы не помним, что было, кто был. Но помним, что что-то было и было плохо или хорошо. А если учесть, что мы привыкли получать информацию опосредованно, то готовы с доверием воспринимать сказанное привычным и авторитетным источником

Если сосредоточиться на повторении негативного акцента в сообщениях или вообще в любых информационных проявлениях относительно данного объекта, а тем более, если исключить, например, из информационного поля всякое положительное (а то и вообще какое-либо) упоминание о нем или постоянно вспоминать о его темных и уязвимых сторонах или ставить в связь с отрицательными явлениями, то эффект может оказаться колоссальным. В массовом сознании не останется ничего, кроме неприязни, самого негативного восприятия (фиксированной установки) при абсолютном незнании предмета. В лучшем случае, складывается подозрительное или настороженное отношение: то ли он украл, то ли у него украли. В худшем отношение полностью вытесняет вторую составляющую стереотипа - знание по формуле: я не могу объяснить, я не знаю, что это такое, но уверен, что это плохо. Таков, в принципе, в долговременной перспективе механизм воздействия средств массовой информации на широкую аудиторию. При этом в случае, когда ставится цель создания положительного отношения к объекту акцент информации неизменно и последовательно делается предпочтительно на положительной информации, положительных акцентах, сочувственном или благожелательном тоне. В этом случае создается не отрицательный, а положительный образ- 
стереотип. Неверно думать, таким образом, будто стереотип - всегда заряжен негативом.

Вопрос о правильном подходе к формированию стереотипа особенно важен при решении задачи по созданию пропагандистского стереотипа - имиджа. Сила пропаганды как распространения и закрепления определенной информации, знаний и т.п. заключается в том, что она подключает много разносторонних установок и создает условия для закрепление фиксированности стереотипа - самого расплывчатого, неясного, а то не несущего в себе никакого конкретного содержания, но эмоционально заряженного образа, лишенного конкретики, но взывающего к однозначной реакции. Те, кто считает, что сам термин «пропаганда» несет в себе негативный заряд, и поэтому пытаются заменить не только термин, но и содержание понятия вместе с практикой его применения понятием и практикой т. н. направленной информации, упускают из виду одно принципиально важное обстоятельство. Направленная информация не подразумевает целенаправленной работы по формированию в аудитории нужных фиксированных установок, этого можно добиться только систематической и многообразно работой по созданию множества подкрепляющих друг друга установок с соответствующими акцентами - созданию стереотипов.

\section{СПИСОК ЛИТЕРАТУРЫ}

Lippman, W. (1972) Public Opinion. N.Y. : Prinston University Press.

Артемов Владимир Львович - доктор исторических наук, профессор, профессор кафедры журналистики Московского гуманитарного университета. Адрес: 111395, Россия, г. Москва, ул. Юности, д. 5. Тел.: +7 (499) 374-60-91. Эл. адрес: dimandi@gmail.com

Artemov Vladimir L'vovich, Doctor of History, Professor, Department of Journalism, Moscow University for Humanities. Postal address: 5 Yunosti St., 111395 Moscow, Russian Federation. Tel.: +7 (499) 374-60-91. E-mail: dimandi@gmail.com 